attention of the meeting to the abuse of authority by the conversion of the workhouses into police-stations in cases of drunkenness. $\mathrm{He}$ bad yet to learn whether the Commissioners had any statutory power so to dispose of their prisoners. Whether they had or had not, the result bad been that profligate women were sent to the metropolitan and large urban workhouses, and the medical officer was called out of his bed to attend them without fee or reward. That question, he thought, should be submitted to the notice of the Home Secretary, and he be asked to see a deputation from the Association for the purpose of laying it before him. As regarded the Superannuation Act, he did not then see any way to procure its alteration so as to make it compulsory.

Mr Porter then laid before the meeting the facts of the case relating to Mr. Beckingsale, medical officer to the $\mathrm{New}$ port (Isle of Wight) Union, who had been directed to resign his appointment in consequence of charges made against him in the case of an idiot who died in the workbon-e. He (Mr. Porter) said the case was a simple one. An idiot, aged twenty, was brought up by his mother, and they understood one another perfectly. By the order of the guardians he was sent into the workhouse, where he pined for his mother, refused to take food, and died after he had been in the workhouse some months. He was wasted to a skeleton, and there was nothing in the stomach. Upon that the jury's verdict was returned "Death from Starvation." A Local Government Board inquiry took place, with the result mentioned. Mr. Beckingsale was deprived of his appointment, and he and his son rendered incapable of holding any other Poor-law appointment.

Mr. Cornwall was of opinion that it was a case in wbich it was the duty of the Association to apply for a mandamus to reverse the decision of the coroner's jury.

After a prolonged discussion, Mr. Cornwall moved as follows:- 'That at the annual meeting of the Poor-law Medical Officers' Association the case of Mr. Beckingsale, medical officer of Newport (Isle of Wight) Union Workhouse, was discussed at considerable length, and it was the unanimous opinion of the meeting that the decision of your Board has been arrived at on imperfect data. The Association, therefore, trusts your Board will reopen the question with the view of taking further evidence in the matter."

Dr. Roberts seconded the motion, to which was added a reyuest that, pending further inquiry, the Board would permit their decision to remain in abeyance, and it was carried.

The secretary reported that the balance in favour of the Association amounted to 2103 . Dr. Hudson, of Redruth, was proposed for membership and accepted, and the meeting terminated.

\section{THE SMALL-POX EPIDEMIC.}

Srall.pox caused 54 deaths during the last seven days of June in twenty of the largest English towns, against numbers declining steadily from 92 to 55 in the seven preceding weeks. These 54 deatbs included 44 in London, 5 in Liverpool, 3 in Oldham, 1 in Salford, and 1 in Leeds; no death was referred to this disease in any of the fifteen other towns. In the outer ring of suburban districts around London 4 fatal cases of small-pox were registered, of which 3 occurred in West Ham and Stratford, and 1 in Bexley.

The registered small-pox deaths in London, which in the seven preceding weeks had slowly but steadily declined from 78 to 44 , were again 44 last week. Of these, 21 occurred in the Metropolitan Asylum hospitals, 2 in the Highgate Small-pox Hospital (which contained 39 patients on the last day of June), and 21 in private dwellings. The 21 fatal cases in private dwellings included 5 in Newington, 3 in Camberwell, 2 in Mile-end, 2 in Bethnal-green, and 2 in Battersea. After distributing the 23 fatal hospital cases, the Registrar-General reports that 5 of the deceased smallpox patients had resided in Islington, 5 in Newington, 4 in Kensington, 4 in Bethnal-green, 3 in Paddington, and 3 in Poplar. The deaths of 8 more children in London, aged under five years, resulted from small-pox during the week.

The number of small-por patients in the Metropolitan Asylum hospitals, which in the firo preceding weeks had steadily declined from 964 to 726, furtber decreased to 664 on the last day of June. The nu uber of new cases admitted to these hospitals was 97 last week, and exceeded that in the previous week by 3 .

\section{Cortespondence.}

\author{
"Audi alteram partem."
}

\section{METROPOLITAN MEDICAL RELIEF.}

\section{To the Editor of THE LANCET.}

SIr,-A meeting was lately held at the rooms of the Society of Arts to hear and discuss a paper by Sir Charles Trevelyan on the subject of metropolitan medical relief, at which Sir William Gull, Mr. Presectt Hewett, and other eminent physicians and surgeons, expressed views tending to show that the present organisation of our out-patient departments is not in a perfectly satisfactory condition. My own opinion to the same effect has long been formed, and $I$ attended that meeting chiefly in order to urge a vier which I bave often stated and upheld, and to which, I am now happy to learn, there is some chance of obtaining practical attention. My ideas may be put shortly thus. Our out-patient rooms ought to be, and might be made, very important centres of medical and surgical teaching, and also important consultative departments-that is, places where persons who cannot afford a fee can obtain opinions for their own guidance and that of their medical attendants, in the same way as richer persons do by consulting the same class of practitioners at home. The cases, therefore, which are most appropriate for out-patient relief are such $a s$, on account of their special nature, their diffeulty, rarity, need of peculiar or prolonged methods of examination, and such like causes, offer obstacles which baffle the medical man, or the institution under whose care the patient has been. Such cases require especially deliberation and care in diagnosis, and therefore should not be received in very large numbers.

As our out-patient departments are at present managed, both these objects are entirely frustrated. The physician or surgeon is oppressed with the number of those pressing upon him for what is called his "advice," and can give no proper attention to the work of teaching, and so this department, which ought to be almost, if not quite, as valuable as the hospital wards for instruction in the all-important art of diagnosis, is almost lost to our medical schools. Meanwhile the poor do not obtain what they think they shall get when they come to the hospital, and what the public who subscribe believe that they get there-namely, the matured judgment and deliberate ad vice of practitioners of recognised skill and eminence. Even if the appointed officer really sees them, it is a mere farce to speak of giving "advice" to such a crowd in such a time, besides all the inconvenience, danger of contagion, loss of time, weariness, exposure to weather, and other drawbacks connected with the attendance of a large number of patients, some of them from great distances. I could easily give instances of what I mean, but I think it hardly necessary ; for I do not doubt that I should be supported by a great majority of those who have served in these departments in saying that this state of things ought to cease; that the indiscriminate and unlimited reception of out-patients on the recommendation of subscribers is bad, their unlimited reception witbout recom. mendations worse, and the reception of a limited number indiscriminately (though an improvement on the above systems) leaves much to be desired, since a very large proportion of the cases are hardly subjects for charity, and afford little or no materials for teaching.

The plan that occurred to me as likely to meet these objections may be thus roughly stated. Let the out-patient department be mainly consultative. ( $I$ would, in fact, restrict the treatment of cases to those who had been in-patients, but this is a matter of detail.) Let the Poor-law infirmaries, the dispensaries, provident or other, and the general practitioners of the district, be permi'ted to send their patients to the out-patient departments for consultation, and let such patients receive the same as private 
consulting patients now receive-viz., a diagnosis and prescription. If the general idea of this plan meets with acceptance, its details would not be difficult to settle. It introduces no new dangers of abuse by persons who can afford to pay, and obviates much of the danger which now exists, since the patients must come through a medical man. Some arrangements might be necessary in order properly to limit the numbers, though it is clear that, if freed from the crowd of trivial cases and of old patients which now oppress him, the physician or surgeon would have ample time for a larger number of new cases than he now receives, and could spend the proper time in their investigation and in demonstrating their practical points to the students. And there would doubtless be uther questions of detail to settle, but my present object in addressing you is not to discuss details, but to ascertain, if possible, what is thought of the general plan. I am no revolutionist, and fully admit the undesirability of disturbing systems to which the public and the profession have become accustomed. But the present indiscriminate out-patient system is of very recent development. It has reached a height at which it ought to be checked, and it can be checked without in any way frustrating the declared objects of our hospitals as charities, and with prospects of immense advantage to them as schools of medicine.

I shall be most happy to discuss the matter, either in public or private, with any gentleman interested in it, as far as I am able; and $I$ understand that a meeting will soon be summoned, at which it can be further ventilated. I am, Sir, yours, \&c.,

T. HoIMES.

Great Cumberland-place, June 27th, 1877.

\section{THE ACTION AGAINST MR. BATTESON.}

To the Editor of THE LANCET.

Sir,-Those who were present during the examination of Dr. Hicks on bebalf of Mr. Batteson, and saw the confusion his undisguised partisanship led him into, will feel no little surprise at his returning in print to a subject which, if only for his own sake, had far better have been allowed to die out in the stage in which it was left in your report of last week.

As an excuse for qualified men who permit assistants of not a single hour's hospital education to attend midwifery and other cases until they terminate fatally, Dr. Hicks writes, "As long as unqualified women can practise midwifery, so long is it absurd to prosecute men for the same act." Dr. Hicks knows well enough, and he admits it lower down in his letter, that no such prosecution as he here supposes has been instituted. Does Dr. Hicks really fail to see that a " mid wife" is known by the public to be but a " mid. wife"; whilst, under the cover of his principal's name and qualification, an uneducated assistant, who is only on a par with a midwife, is believed by the poor to be "a regular doctor"? In the first instance, the ignorant, when engaging with a midwife, are not deceived; but in the second, when an engagement is made, a very serious deception takes place.

Dr. Hicks next says, "Now, one of the assistants engaged in the case referred to was a fourth-year's student at the Lond"n Hospital"; but Dr. Hicks knows that this gentleman (Mr. Grigg) saw the deceased only upon two occasions, each of about ten minutes' duration, before her confinement, and that the other assistant (Mr. Smyth), who had the charge of her from 7 A.s. on the Monday until 11 P M. on the Wednesday, when she was instrumentally delivered in a state of "collapse" by them both, is a voung man who has had no hospital education whatever. Dr. Hicks says that "most of the hospital lying-in charities of London are attended on much the same plan as cases were under Mr. Batteson." Is this true? Does Dr. Hicks know of one such charity where women in difficult labour are entrusted to young men who have not received one hour's hospital edueation? Dr. Hicks says that it was contended for the prosecution that, because the average of first cases generally ended in about twenty-four hnurs, therefore it was necessary to do something after that time, although no urgent symptom may arise, which is simple nonsense. No such contention was made, but it was contended that as Mr. Batteson had seen the patient at 11 A.M. on the Monday, and had then formed an opinion that the labour would be over in abont twentyfour b 'urs' time, and, as it had not, terminated for long after that time, that it was his duty to have ayain visited ber, to ascertan what it might have been necessary to bave done to effect delivery. Dr. Hicks is right in saying that it was maintained that perforation should have been preferred to a forceps delivery. It was admitted that a face presentation was found on the Monday morning, that the pelvis at that time was known to be contracted, and that the parts through which the head had to pass subsequently became much swollen from pressure. It was, therefore, contended that the better plan would have been to lessen the bulk of the head of the child, rather than to drag it through a passage too small for it to pass naturally. The laceration of the perineum, which extended to the sphincter, and the rent in the walls of the vagina, would thus have been saved. Does Dr. Hicks teach that thre is vo occasion to examine the perineum in delivering by forceps? He implies so. The point, however, of the choice of instruments was a minor one. The chief ground of complaint was that deceased had not been delivered from twelve to twenty bours earlier, and before exhaustion - "collapse"-from which sbe never rallied, had occurred. It was maintained too, that she ought not to have been left without medical aid from a few minutes after delivery, when she was in a fainting condition, to the time of her death, six hours afterwards. Dr. Hicks says that it could not be wondered at that a trial should be brought by her busband. This can mean nothing else but that the husband had cause to bring his trial, and on that point I quite agree with Dr. Hicks. Dr. Hicks implies that the East London Medical Defence (now Medical Alliance) Association found funds for the prosecution. He heard this emphatically denied in court, yet he repeats it in print. But he does more than that: he implies that the members of the Association do just as Mr. Batteson did; and then he adds openly that the action was the action of one medical man against another, both of which statements are wholly and absolutely untrue.

I am, Sir, your obedient servant,

R. H. S. Carpenter,

June 25th, 1877. Hon. Sec. Medical Alliance Association.

To the Editor of THE LANCET.

Sir,-Permit me to make the following corrections to $\mathrm{Mr}$. Pridham's very inaccurate letter :-

The mistake about Dr. Hicks's evidence is so obvious as not to require refuting. As to the bewilderment of those medical men in court who heard Dr. Hicks's evidence, it can only apply to two members of the East London Medical Defence Association, and no doubt they were bewildered. One could not have expected anything otherwise. The proverbial staring of ducks at thunder would be a tame illustration of the condition of these two gentlemen listening to evidence from a man like Dr. Hicks.

Mr. Pridham says the action has nothing to do with unqualified assistants. Then will he kindly explain Dr. Carpenter's connexion with the case? Such statement also is at variance with another statement made by one of the above-named members of the East London Medical Defence Association. In passing I may notice Dr. Carpenter's assertion that the East London Medical Defence Association had nothing to do with this case. Will Dr. Carpenter undertake to say that no member of that Association has to his knowledge or belief directly or indirectly contributed to the expenses of the late inquest or trial, or is likely to contribute to such expensea? Mr. Pridham says he was retained by the husband, and attended the inquest on his behalf. The husband swore be had not employed Mr. Pridham to attend the inquest, and had never even seen him before that occasion; that he had only paid one guinea towards the expenses of the inquest and trial, and had no jdea who was going to pay; that his wages were thirty shillings a week; and that at the inquest Mr. Pridham's clerk came up to him and offered Mr. Pridham"s card, and told him that if he would go up to their office in Bedford-row they would take the case up for him, or some words to that effect.

Sir Walter Riddell, the learned judge, in delivering his verdict, said (I am quoting from a copy of the shorthand notes)- "I don't care whether this is an attorney's action, or whether it has been got up by one rival practitioner 